\title{
Erratum: Plasmepsin V shows its carnivorous side
}

Daniel E Goldberg

Nat. Struct. Mol. Biol. 22, 647-648 (2015); published online 3 September 2015; corrected after print 12 October 2015.

In the version of this article initially published, the strapline mistakenly described a crystal structure of the Plasmodium falciparum enzyme. Plasmodium vivax is the correct species. The error has been corrected in the HTML and PDF versions of the article.

\section{Corrigendum: Structure and multistate function of the transmembrane electron transporter CcdA}

Jessica A Williamson, Seung-Hyun Cho, Jiqing Ye, Jean-Francois Collet, Jonathan R Beckwith \& James J Chou Nat. Struct. Mol. Biol. 22, 809-814 (2015); published online 21 September 2015; corrected after print 16 October 2015

In the version of this article initially published, the support to Jonathan R. Beckwith from the US National Institutes of Health (grant GMO41883) was not present. The error has been corrected in the HTML and PDF versions of the article. 